\title{
Matrix Metalloproteinase Levels in the Differentiation of Parapneumonic Pleural Effusions
}

\author{
Smaragda Oikonomidi ${ }^{a} K_{\text {Konstantinos Kostikas }}{ }^{a}$ loannis Kalomenidis ${ }^{b}$ \\ Irene Tsilioni $^{\mathrm{a}}$ Christos Daenas $^{\mathrm{a}}$ Konstantinos I. Gourgoulianis ${ }^{\mathrm{a}}$ \\ Theodoros S. Kiropoulos ${ }^{a}$

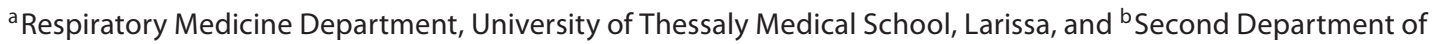 \\ Pulmonary Medicine, Medical School of Athens University, 'Atticon' Hospital, Haidari, Greece
}

\section{Key Words}

Empyema · Fibrosis • Matrix metalloproteinases •

Pleural effusion · Pleural infection

\begin{abstract}
Background: Matrix metalloproteinases (MMPs) have been implicated in the escalation of fibrosis and remodeling which are central to the subsequent progression of a parapneumonic pleural effusion to empyema. Objectives: The aim of this study was the assessment of MMP-2, MMP-8 and MMP-9 in parapneumonic pleural effusions in order to examine their value in the differentiation between uncomplicated and complicated parapneumonic effusions. Methods: The study included 208 consecutive patients with pleural effusions 60 parapneumonic (27 uncomplicated parapneumonic, 17 complicated parapneumonic, 16 empyemas), 24 tuberculous, 89 malignant and 35 transudates]. Concentrations of pleural fluid and serum MMP-2, MMP-8 and MMP-9 were determined by immunoassay. Results: Pleural fluid MMP-8 and MMP-9 levels were higher in complicated parapneumonic effusions or empyema than in uncomplicated effusions, while their serum levels were higher in complicated parapneumonic effusions. MMP-2 levels were higher in uncomplicated than in complicated parapneumonic effusions or empyema. Pleural fluid MMP-2/MMP-9 ratio was the
\end{abstract}

best marker to differentiate complicated from uncomplicated parapneumonic effusions, with a sensitivity of $94.1 \%$ and a specificity of $77.8 \%$ at a cut-off point of 1.32 (AUC $=0.887$ ). Conclusions: Pleural fluid MMP-2, MMP-8 and MMP-9 may provide useful information for differentiating between uncomplicated and complicated parapneumonic effusions.

Copyright $\odot 2010$ S. Karger AG, Basel

\section{Introduction}

Matrix metalloproteinases (MMPs) are zinc-dependent endopeptidases which cause degradation of almost all extracellular matrices [1-3]. MMPs have been implicated in the pathogenesis of various lung diseases, such as lung cancer $[4,5]$, asthma $[6,7]$, chronic obstructive pulmonary disease $[8,9]$, acute lung injury [10], interstitial lung diseases [11] and pleural effusions [12]. Previous studies [13-15] have shown that the expression of MMPs in the pleural space is altered in a variety of inflammatory and malignant diseases, suggesting that certain members of the MMP family may participate in the formation of pleural effusions. The activity of MMPs within the pleural space may play a role in the formation of pleural effusions by altering the integrity of the mesothelial and endothelial cell layer and increasing vascular permeability [16-18].

\section{KARGER}

Fax +41613061234 E-Mail karger@karger.ch www.karger.com
(C) 2010 S. Karger AG, Basel

0025-7931/10/0804-0285\$26.00/0

Accessible online at:

www.karger.com/res
Dr. Theodoros S. Kiropoulos, MB, PhD

Respiratory Medicine Department, University of Thessaly Medical School

University Hospital of Larissa

GR-41110 Larissa (Greece)

Tel. +30 697771 8929, Fax +30 241067 0240, E-Mail ktheod@med.uth.gr 
Table 1. Demographic data and pleural fluid characteristics of the study population $(\mathrm{n}=208)$

\begin{tabular}{|c|c|c|c|c|}
\hline & \multirow{2}{*}{$\begin{array}{l}\text { Transudates } \\
(\mathrm{n}=35)\end{array}$} & \multicolumn{3}{|l|}{ Exudates } \\
\hline & & Malignant $(\mathrm{n}=89)$ & Tuberculous $(\mathrm{n}=24)$ & Parapneumonic $(n=60)$ \\
\hline Age, years & $74.2 \pm 15.9$ & $66.2 \pm 10.4$ & $50.9 \pm 18.9$ & $58.9 \pm 16.9$ \\
\hline Male/female, $\mathrm{n}$ & $24 / 11$ & $62 / 27$ & $17 / 7$ & $49 / 11$ \\
\hline \multicolumn{5}{|l|}{ Pleural fluid } \\
\hline Cells & $500(417.5-1,000)$ & $1,865(1,250-3,500)^{\mathrm{a}, \mathrm{b}}$ & $3,239 \pm 2,385^{\mathrm{a}, \mathrm{b}}$ & $6,200(2,988-41,300)^{\mathrm{a}}$ \\
\hline Lymphocytes, \% & $45.4 \pm 28.6$ & $56.2 \pm 26.1^{\mathrm{b}}$ & $78.6 \pm 11.0^{\mathrm{a}-\mathrm{c}}$ & $10(5-19)^{\mathrm{a}}$ \\
\hline Neutrophils, \% & $28.7 \pm 33.8$ & $10(3.5-20.5)^{\mathrm{b}}$ & $15.4 \pm 10.5^{\mathrm{b}}$ & $74.2 \pm 18.2^{\mathrm{a}}$ \\
\hline Glucose, $\mathrm{mmol} / \mathrm{l}$ & $0.7 \pm 0.2$ & $0.6 \pm 0.3$ & $0.5 \pm 0.2^{\mathrm{a}}$ & $0.5 \pm 0.4$ \\
\hline $\mathrm{pH}$ & $7.4 \pm 0.1$ & $7.4 \pm 0.1^{\mathrm{b}}$ & $7.3 \pm 0.1$ & $7.2 \pm 0.3$ \\
\hline \multicolumn{5}{|l|}{ Total protein } \\
\hline In pleural fluid, $\mathrm{g} / \mathrm{l}$ & $3.1 \pm 0.8$ & $4.4 \pm 1.2^{\mathrm{a}}$ & $5.4 \pm 0.6^{\mathrm{a}-\mathrm{c}}$ & $4.4 \pm 1.3^{\mathrm{a}}$ \\
\hline In serum, $\mathrm{g} / \mathrm{l}$ & $6.6 \pm 0.8$ & $6.7 \pm 0.9$ & $7.2 \pm 0.7^{\mathrm{b}}$ & $6.4 \pm 0.8$ \\
\hline Pleural fluid/serum ratio & $0.5 \pm 0.1$ & $0.7(0.6-0.7)^{\mathrm{a}}$ & $0.8 \pm 0.1^{\mathrm{a}, \mathrm{c}}$ & $0.7 \pm 0.2^{\mathrm{a}}$ \\
\hline \multicolumn{5}{|l|}{ Lactate dehydrogenase } \\
\hline In pleural fluid, U/l & $148.6 \pm 102.3$ & $305(201.5-556)^{\mathrm{a}, \mathrm{b}}$ & $633.2 \pm 389.7^{\mathrm{a}}$ & $1,134(518-2,626)^{\mathrm{a}}$ \\
\hline In serum, $U / 1$ & $270.8 \pm 120.2$ & $238(192-311.5)$ & $212.2 \pm 62.3$ & $212.5(158.5-288)$ \\
\hline Pleural fluid/serum ratio & $0.8 \pm 0.9$ & $1.3(0.8-2.1)^{\mathrm{a}, \mathrm{b}}$ & $3.3 \pm 2.3^{\mathrm{a}, \mathrm{c}}$ & $4.9(2.4-11.9)^{\mathrm{a}}$ \\
\hline
\end{tabular}

Data are means \pm SD for normally distributed data or medians (interquartile ranges) for skewed data.

${ }^{a} \mathrm{p}<0.05$ exudates vs. transudates; ${ }^{\mathrm{b}} \mathrm{p}<0.05$ tuberculous or malignant effusions vs. parapneumonic effusions; ${ }^{\mathrm{c}} \mathrm{p}<0.05$ tuberculous vs. malignant effusions.

Parapneumonic pleural effusions (PPEs) - i.e. effusions secondary to pneumonia - most frequently are constituted by sterile reactive fluid and resolve with appropriate antibiotic therapy (uncomplicated parapneumonic pleural effusions, UPPEs) $[19,20]$. However, in some cases, the pleural fluid gets infected, with resultant escalating intrapleural inflammation and fibrosis leading to the formation of adhesions and pleural fluid loculations. In these cases, invasive treatment such as pleural drainage and sometimes surgery is required, and the effusions are called complicated parapneumonic pleural effusions (CPPEs). If a CPPE is not appropriately treated, it will most probably evolve into pleural empyema $[21,22]$. The differentiation between UPPE and CPPE is of critical importance, because it influences therapeutic decisions that affect patient outcomes [21]. For many years the classic biochemical parameters of the pleural fluid were considered to be the most useful indexes for identifying CPPE, and $\mathrm{pH}$ is the most widely used guide to indicate the need for pleural drainage in this condition [21,23-25]. Despite these classification tools, the diagnosis of CPPE is still delayed in some patients.

MMPs are interesting candidate markers, since they have been implicated in the escalation of fibrosis and remodeling which are central to the subsequent pro- gression of a PPE to empyema [26]. A previous study showed that empyemas or CPPE contain higher concentrations of MMP-1, MMP-8 and MMP-9 compared to other exudates and UPPE [14]. However, in this study the possible discriminative ability of MMP levels was not evaluated.

The aim of the present study was to evaluate the levels of MMP-2, MMP-8 and MMP-9 in the pleural fluid and serum of patients with pleural effusions. We also examined whether MMP-2, MMP-8 and MMP-9 could serve as independent markers for the differentiation between CPPE and UPPE.

\section{Materials and Methods}

\section{Study Group}

This study was performed on patients who were hospitalized in the Respiratory Medicine Department of the Medical School of the University of Thessaly in Larissa between September 2005 and November 2008. We stored pleural fluid and serum samples and recorded their clinical and laboratory data. For the purpose of the study, 208 consecutive patients who had undergone diagnostic thoracentesis for pleural effusions were studied (table 1). Seventyeight of these patients had been included in another study of our department [27]. 
The determination of the etiology of the pleural effusions was based on clinical presentation, results of diagnostic tests, and/or response to treatment for each patient. Accordingly, effusions were classified into the following groups by predetermined criteria [28]:

(1) Malignant effusions were diagnosed by the demonstration of malignant cells on cytologic examination or in biopsy specimens.

(2) Tuberculous effusions were diagnosed based on the presence of positive stain or culture for Mycobacterium tuberculosis in pleural fluid, sputum, or pleural biopsy specimens; or in the presence of granulomas, on pleural biopsy specimens after exclusion of other granulomatous diseases.

(3) PPEs were effusions associated with pneumonia. The classification of parapneumonic effusions into UPPE, CPPE and empyemas was based on the British Thoracic Society guidelines [29]. UPPE successfully resolved with antibiotics alone. These effusions were identified by non-purulent pleural fluid, negative microbiological studies in pleural fluid, pleural fluid $\mathrm{pH}$ $>7.2$, pleural fluid lactate dehydrogenase $(\mathrm{LDH})<1,000 \mathrm{IU} / 1$ and fluid glucose $>2.2 \mathrm{mmol} / \mathrm{l}$. CPPE were non-purulent-appearing effusions that did not resolve without chest tube or any other drainage method. These effusions met at least 1 of the following criteria: (a) an inadequate clinical response to antibiotics treatment alone (i.e. persistent fever, pain, or increased effusions) with resolution after tube drainage; (b) a progression of the effusion to loculation or fibrothorax; (c) pleural fluid $\mathrm{pH}<7.2$; (d) pleural fluid $\mathrm{LDH}>1,000 \mathrm{IU} / \mathrm{l}$, and (e) pleural fluid glucose $<2.2 \mathrm{mmol} / \mathrm{l}$. Finally, empyema was defined as a condition in which the diagnostic thoracocentesis yielded gross pus, or a positive Gram stain or bacterial culture of the pleural effusion. It has to be stressed that the identification of an empyema led in all cases to the insertion of a thoracic tube [30].

(4) The diagnosis of congestive heart failure was based on the findings of an enlarged heart and/or pulmonary venous congestion on a chest radiograph, evidence of left ventricular systolic or diastolic dysfunction on echocardiography, and/or response to treatment for congestive heart failure.

Classification of effusions was made by two experienced clinicians (K.K. and K.I.G.) blinded to the measurements of MMP-2, MMP-8 and MMP-9 at the time of the diagnosis. The characterization of effusions as exudates was further validated using the criteria of Light et al. [31]. Parapneumonic, tuberculous and malignant effusions were exudates, whereas effusions due to congestive heart failure were transudates. The study protocol was approved by the local ethics committee and all subjects provided written informed consent.

\section{Specimen Collection and Processing}

Pleural fluid samples were collected with the first successful thoracentesis before treatment. Simultaneously, $10 \mathrm{ml}$ of venous blood were obtained. Samples were immediately analyzed by standard methods for total and differential cell counts (Gen S, Beckman Coulter), glucose, total protein and LDH (Olympus AU $600)$. Aliquots of pleural fluid and serum samples were immediately centrifuged at $1,500 \mathrm{~g}$ for $15 \mathrm{~min}$ at $4^{\circ} \mathrm{C}$ to pellet the cellular elements, and the supernatants were stored at $-80^{\circ} \mathrm{C}$ for MMP-2, MMP-8 and MMP-9 measurements.

Metalloproteinases in Pleural Infection

\section{Enzyme Immunoassay}

The immunoreactive levels of MMP-2, MMP-8 and MMP-9 were determined in the supernatants of pleural effusions utilizing sandwich enzyme immunoassays (R\&D Systems, Minneapolis, Minn., USA).

\section{Statistical Analysis}

Normally distributed data are presented as means \pm SD and skewed data are presented as the median, 25 th and 75 th quartiles. The normality of distribution was checked with a Shapiro-Wilks test. Comparison among groups was performed using analysis of variance (ANOVA) on ranks (Kruskal-Wallis) with post-hoc pairwise testing (Dunn's method). Differences were regarded as statistically significant at $\mathrm{p}<0.05$. To evaluate the usefulness of MMP-2, MMP-8 and MMP-9 levels in differentiating between UPPE and CPPE, receiver operator characteristic (ROC) analysis was performed, and the area under the curve (AUC) was calculated. The optimum cut-off point from ROC analysis was established by selecting the value that provides the greatest sum of sensitivity and specificity, i.e. the point closest to the upper left corner of the ROC plot. For the optimum cut-off point provided by each ROC analysis, sensitivity, specificity, positive likelihood ratio, negative likelihood ratio, positive predictive value, and negative predictive value were calculated using standard formulas. Statistical analysis was performed using MedCalc 9.0 (MedCalc, Mariakerke, Belgium) and GraphPad Prism 5.0 software (GraphPad Software, San Diego, Calif., USA).

\section{Results}

\section{General Characteristics of Pleural Effusions}

The demographic data and the pleural fluid characteristics of the 208 patients that were included in the study are presented in table 1.

Pleural fluid MMP-2 levels were higher in malignant pleural effusions than in transudative, tuberculous and parapneumonic effusions. Patients with infectious diseases (tuberculous and, especially, parapneumonic effusions) were characterized by higher pleural fluid and serum MMP-8 and MMP-9 levels and pleural fluid/serum MMP-8 and MMP-9 ratios, while the lowest values were observed in patients with transudates (table 2).

\section{MMP-2, MMP-8 and MMP-9 in Parapneumonic Pleural Effusions}

The levels of MMP-2, MMP-8 and MMP-9 in pleural fluid, serum and pleural fluid to serum ratio of patients with UPPE, CPPE or empyema are presented in table 3.

The pleural fluid concentration of MMP-2 was significantly higher in patients with UPPE than in those with CPPE ( $p<0.01)$ or empyema $(p<0.01)$. Pleural fluid MMP-8 levels were significantly higher in CPPE or empyema than in UPPE $(p<0.01$ and $p<0.0001$, respec- 
Table 2. Levels of MMP-2, MMP-8 and MMP-9 in the pleural fluid and serum of patients with pleural effusions

\begin{tabular}{lcccc}
\hline & \multirow{2}{*}{$\begin{array}{l}\text { Transudates } \\
(\mathrm{n}=35)\end{array}$} & Exudates & & \\
\cline { 4 - 5 } & & Malignant $(\mathrm{n}=89)$ & Tuberculous $(\mathrm{n}=24)$ & Parapneumonic $(\mathrm{n}=60)$ \\
\hline MMP-2 & & & $351.7 \pm 170.1^{\mathrm{b}, \mathrm{c}}$ \\
PF, ng/ml & $374.9(330.0-501.3)$ & $522.6 \pm 139.2^{\mathrm{a}}$ & $491.6 \pm 95.93$ & $159.2(134.30-192.8)^{\mathrm{a}, \mathrm{c}}$ \\
Serum, ng/ml & $232.4 \pm 68.21$ & $191.9(158.4-231.3)$ & $136.8 \pm 21.13^{\mathrm{a}, \mathrm{d}}$ & $2.26(1.66-2.67)^{\mathrm{b}, \mathrm{c}}$ \\
PF/S ratio & $1.89 \pm 0.46$ & $2.77 \pm 0.77^{\mathrm{a}}$ & $3.48 \pm 0.55^{\mathrm{a}, \mathrm{d}}$ & \\
MMP-8 & & & & \\
PF, ng/ml & $0.28(0.06-3.3)$ & $4.64(0.48-15.97)^{\mathrm{a}}$ & $31.06(7.34-76.66)^{\mathrm{a}, \mathrm{d}}$ & $222.8(27.71-300.9)^{\mathrm{a}, \mathrm{c}}$ \\
Serum, ng/ml & $20.94(12.21-48.6)$ & $26.42(13.03-51.83)$ & $36.37(13.78-62.95)$ & $64.84(27.92-130.9)^{\mathrm{a}, \mathrm{c}}$ \\
PF/S ratio & $0.01(0.00-0.04)$ & $0.16(0.04-0.80)^{\mathrm{a}}$ & $0.8(0.16-2.35)^{\mathrm{a}}$ & $2.22(0.85-5.05)^{\mathrm{a}, \mathrm{c}}$ \\
MMP-9 & & & & \\
PF, ng/ml & $10.1(5.70-17.33)$ & $23.15(11.13-49.0)^{\mathrm{a}}$ & $75.2(37.75-97.15)^{\mathrm{a}, \mathrm{d}}$ & $496.0(59.63-1,548)^{\mathrm{a}, \mathrm{c}}$ \\
Serum, ng/ml & $443.5(251.2-792.3)$ & $655.7(419.1-914.1)$ & $730.1 \pm 392.9$ & $810.8(528.5-1,302)^{\mathrm{a}}$ \\
PF/S ratio & $0.02(0.01-0.06)$ & $0.03(0.02-0.11)$ & $0.09(0.07-0.29)^{\mathrm{a}}$ & $0.68(0.14-1.99)^{\mathrm{a}, \mathrm{c}}$ \\
\hline
\end{tabular}

Data are means \pm SD for normally distributed data or medians (interquartile ranges) for skewed data. $\mathrm{PF}=\mathrm{Pleural}$ fluid; $\mathrm{PF} / \mathrm{S}=$ pleural fluid/serum.

${ }^{a} \mathrm{p}<0.05$ exudates vs. transudates; ${ }^{b} \mathrm{p}<0.05$ parapneumonic vs. tuberculous effusions; ${ }^{\mathrm{c}} \mathrm{p}<0.05$ parapneumonic vs. malignant effusions; ${ }^{\mathrm{d}} \mathrm{p}<0.05$ tuberculous vs. malignant effusions.

Table 3. Levels of MMP-2, MMP-8 and MMP-9 in pleural fluid and serum of patients with uncomplicated parapneumonic pleural effusion (UPPE), complicated parapneumonic pleural effusion (CPPE) and empyema

\begin{tabular}{lccc}
\hline & UPPE $(\mathrm{n}=27)$ & CPPE $(\mathrm{n}=17)$ & Empyema $(\mathrm{n}=16)$ \\
\hline MMP-2 & & & \\
PF, ng/ml & $451.9 \pm 115.1$ & $290.0 \pm 90.68^{\mathrm{a}}$ & $295.7(19.39-457.2)^{\mathrm{b}}$ \\
Serum, ng/ml & $174.9(142.6-213.1)$ & $146.2 \pm 34.4$ & $171.5 \pm 47.47$ \\
PF/S ratio & $2.52 \pm 0.61$ & $2.02 \pm 0.55$ & $1.52 \pm 1.26^{\mathrm{b}}$ \\
MMP-8 & & & \\
PF, ng/ml & $27.71(6.68-179.6)$ & $264.6 \pm 123.3^{\mathrm{a}}$ & $284.6 \pm 110.1^{\mathrm{b}}$ \\
Serum, ng/ml & $45.6(23.82-97.58)$ & $99.08(57.22-157.7)$ & $64.84(29.31-184.4)$ \\
PF/S ratio & $0.77(0.31-2.45)$ & $2.17(1.16-7.0)$ & $2.52(2.02-7.77)^{\mathrm{b}}$ \\
MMP-9 & & & \\
PF, ng/ml & $59.8(15.7-282.1)$ & $1,042 \pm 812.4^{\mathrm{a}}$ & $1,772 \pm 767.4^{\mathrm{b}}$ \\
Serum, ng/ml & $633.3(390.60-1,056)$ & $1,220 \pm 533.5^{\mathrm{a}}$ & $839.6 \pm 454.6$ \\
PF/S ratio & $0.14(0.01-0.63)$ & $0.48(0.27-1.3)$ & $3.01(1.08-3.57)^{\mathrm{b}, \mathrm{c}}$ \\
\hline
\end{tabular}

Data are means \pm SD for normally distributed data or medians (interquartile ranges) for skewed data. $\mathrm{PF}=$ Pleural fluid; $\mathrm{PF} / \mathrm{S}=$ pleural fluid/serum.

${ }^{\mathrm{a}} \mathrm{p}<0.05$ CPPE vs. UPPE; ${ }^{\mathrm{b}} \mathrm{p}<0.05$ empyema vs. UPPE; ${ }^{\mathrm{c}} \mathrm{p}<0.05$ empyema vs. CPPE.

tively; table 3, fig. 1). No significant differences were observed in serum MMP-2 and MMP-8 levels between UPPE, CPPE and empyema. Pleural fluid MMP-9 levels were significantly higher in empyema compared to UPPE $(\mathrm{p}<0.0001)$ and in CPPE compared to UPPE $(\mathrm{p}<0.01)$, while the serum levels were significantly higher in patients with CPPE than in those with UPPE $(\mathrm{p}<0.05$; table 3 , fig. 1).

\section{Diagnostic Performance for Differentiating UPPE and} CPPE

The diagnostic performance of pleural fluid MMP-2, MMP-8 and MMP-9 according to the ROC analysis is presented in table 4. Pleural fluid concentrations were more useful than serum concentrations or the pleural fluid/serum ratios in discriminating between UPPE and CPPE (data not presented). A low MMP-2 and a high 
Table 4. Diagnostic performance of pleural fluid MMP-2, MMP-8 and MMP-9 for differentiating CPPE and UPPE

\begin{tabular}{|c|c|c|c|c|c|c|c|c|}
\hline & Optimal cut-off point & Sensitivity, \% (95\% CI) & Specificity, \% (95\% CI) & $+\mathrm{LR}$ & $-\mathrm{LR}$ & PPV, \% & NPV, \% & AUC (95\% CI) \\
\hline MMP-2 & $\leq 343.15 \mathrm{ng} / \mathrm{ml}$ & $82.4(56.6-96.0)$ & $85.2(66.3-95.7)$ & 5.56 & 0.21 & 77.8 & 88.5 & $0.858(0.720-0.945)$ \\
\hline MMP-8 & $>115.8 \mathrm{ng} / \mathrm{ml}$ & $86.7(59.5-98.0)$ & $73.1(52.2-88.4)$ & 3.22 & 0.18 & 65.0 & 90.5 & $0.813(0.660-0.917)$ \\
\hline MMP-9 & $>208.2 \mathrm{ng} / \mathrm{ml}$ & $88.2(63.5-98.2)$ & $74.1(53.7-88.8)$ & 3.40 & 0.16 & 68.2 & 90.9 & $0.854(0.715-0.942)$ \\
\hline MMP-2/MMP-9 & $\leq 1.32$ & $94.1(71.2-99.0)$ & $77.8(57.7-91.3)$ & 4.24 & 0.08 & 72.7 & 95.5 & $0.887(0.755-0.962)$ \\
\hline MMP-2/MMP-8 & $\leq 2.3$ & $88.2(63.5-98.2)$ & $81.5(61.9-93.6)$ & 4.76 & 0.14 & 75.0 & 91.7 & $0.876(0.741-0.955)$ \\
\hline MMP-8/MMP-9 & $\leq 0.22$ & $64.7(38.4-85.7)$ & $77.8(57.7-91.3)$ & 2.91 & 0.45 & 64.7 & 77.8 & $0.624(0.465-0.765)$ \\
\hline
\end{tabular}

$+\mathrm{LR}=$ Positive likelihood ratio; $-\mathrm{LR}=$ negative likelihood ratio; $\mathrm{PPV}=$ positive predictive value; $\mathrm{NPV}=$ negative predictive value; $\mathrm{AUC}=$ area $\mathrm{under}$ the curve; $\mathrm{CI}=$ confidence intervals.

MMP-9 pleural fluid content are almost equally effective in differentiating CPPE from UPPE, while MMP-8 was marginally inferior, as indicated by the AUCs. The combination of low MMP-2 with high MMP-8 or high MMP-9 slightly improved the performance of the single measurements. Notably, a MMP-2/MMP-9 ratio >1.32 represents the strongest predictor against a complicated parapneumonic effusion with a negative likelihood ratio of 0.08 .

\section{Discussion}

In the present study, MMP-2, MMP-8 and MMP-9 were measured in the pleural fluid and serum of patients with pleural effusions. Our main findings are: (1) the highest pleural fluid and serum MMP-8 and MMP-9 levels are in patients with PPE; (2) pleural fluid levels of MMP- 8 and MMP-9 are increased in CPPE and empyemas compared to UPPE, while pleural fluid MMP-2 levels are decreased in CPPE and empyemas compared to UPPE; (3) MMP-2 and MMP-9 measurements in the pleural fluid performed equally for the differentiation between UPPE and CPPE, whereas MMP-2/MMP-9 provided the best performance for the differentiation between UPPE and CPPE. Our data suggest that measurements of these two MMPs in pleural fluid may be helpful for the differentiation between UPPE and CPPE.

Several previous reports demonstrated the presence and enzymatic activities of these MMPs in pleural effusions of different origin, suggesting that these enzymes may play a role in the homeostasis of pleural space and are induced in specific disease states $[12,13,15]$. Iglesias et al. [14] showed that empyemas or CPPE contain significantly higher concentrations of MMP-8 and MMP-9 as compared to other exudates and UPPE. Our results are in agreement with the above findings, as the levels of

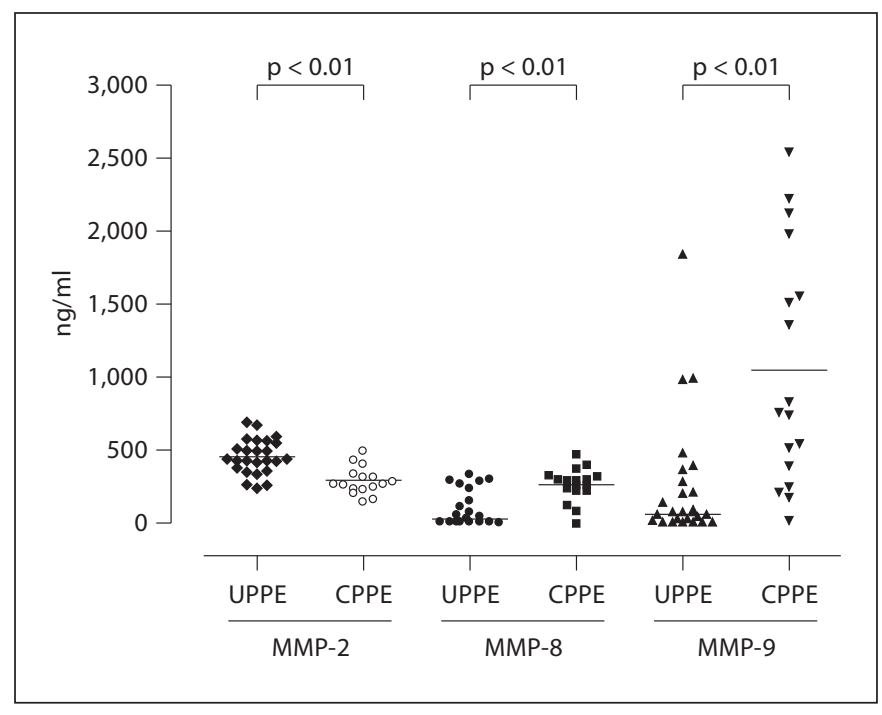

Fig. 1. Levels of MMP-2, MMP-8 and MMP-9 in the pleural fluid of patients with UPPE and CPPE. Each symbol represents one individual and horizontal bars represent mean values. The $\mathrm{p}$ values represents statistical significance among the 3 groups.

MMP-8 and MMP-9 were highest in CPPE followed by UPPE. Table 3 shows that MMP- 8 is 10 -fold higher in CPPE as compared to UPPE and that MMP-9 is 20 -fold higher in CPPE as compared to UPPE. Furthermore, we demonstrated that patients with empyema were characterized by the highest pleural fluid/serum MMP-9 ratios which, in contrast to those with other diagnoses, were $>1$, suggesting local production in the pleural cavity. These findings may be explained by the intense neutrophilic response observed in the empyema, since MMP-8 and MMP-9 are stored in the neutrophil granules [14]. On the other hand, the constant presence of MMP-2 in pleural effusions should be more likely attributed to constitutive MMP-2 expression by mesothelial cells and the fact that, 
in contrast to MMP-9, inflammatory stimuli do not affect MMP-2 expression by mesothelial cells [32, 33]. These observations indicate that MMP-8 and MMP-9 but not MMP-2 may participate in the escalation of the pleural inflammatory and fibrotic reaction in patients with advanced disease.

Pleural fluid drainage is required in patients with pleural infection (empyema or CPPE), while antibiotic treatment is adequate for UPPE; that means that the differentiation between these patients is of major clinical importance. Patients with frank pus in their pleural cavity are easily recognized, and in all such patients the insertion of a thoracic tube is indicated. On the other hand, in order to discriminate between non-purulent UPPE and CPPE which often look alike, current guidelines suggest that the biochemical characteristics of the pleural fluid should be examined. In connection to this, a low pleural fluid $\mathrm{pH}(<7.20)$, a low glucose $(<2.2 \mathrm{mmol} / \mathrm{l})$ and a high $\mathrm{LDH}$ value $(>1,000 \mathrm{IU} / \mathrm{l})$ usually indicate the need for drainage $[23,34]$. A meta-analysis of these 3 biochemical indexes revealed that pleural fluid $\mathrm{pH}(\mathrm{AUC}=0.89)$ was slightly more effective in identifying non-purulent CPPE than pleural fluid glucose or LDH $($ AUC $=0.71)$ [35]. Porcel et al. [21] found a considerable overlap between the AUC values for $\mathrm{pH}(\mathrm{AUC}=0.78)$, glucose $(\mathrm{AUC}=0.82)$ and $\mathrm{LDH}(\mathrm{AUC}=0.86)$, but there was a trend toward a better accuracy of the latter, mainly because of its superior sensitivity. As reported in this study, 12 of 22 patients (55\%) with PPE who ultimately underwent drainage exhibited pleural $\mathrm{pH}$ and glucose levels $>7.20$ and $>60 \mathrm{mg} / \mathrm{dl}$, respectively.

Clinical judgment, including patient evaluation and information obtained from chest X-rays and CT scans, remains the cornerstone of treatment decisions in the management of parapneumonic effusions, including the insertion of chest tubes or surgical interventions. However, biomarkers that provide information for the development of complicated parapneumonic effusions or empyemas may provide additional information to the attending physician in order to facilitate treatment decisions. Several biochemical markers such as myeloperoxidase [36], TNF- $\alpha$ [21] or C-reactive protein [37] have been proposed to assist decision-making regarding clinical management. In the present study we examined the diagnostic accuracy of MMPs for the differentiation between UPPE and CPPE. Pleural fluid MMP-2/MMP-9 ratio was the best marker to differentiate between the two types of PPE, with a sensitivity of $94.1 \%$ and a specificity of $77.8 \%$ at a cut-off point of $1.32(\mathrm{AUC}=0.887)$. Notably, a MMP2/MMP-9 ratio $>1.32$ is the strongest predictor against a
CPPE with a negative likelihood ratio of 0.08 . Additionally, we have shown that even single measurements of either one of these MMPs were characterized by a satisfactory diagnostic accuracy. In contrast, serum levels and pleural fluid/serum ratio of MMPs could not effectively discriminate between UPPE and CPPE. We could thus assume that pleural fluid but not serum levels of MMPs may be helpful in detecting pleural infection and guiding the decision to drain a PPE.

Our study has several limitations. Firstly, the definition of CPPE was based on the subjective clinician judgment to drain the pleural space, according to the British Thoracic Society guidelines [29], a fact that may lead to misclassification of some patients with PPE. Another major limitation of the study presented here is the fact that the diagnostic performance of the markers under investigation could not be reliably compared with that of conventional markers, such as pleural fluid $\mathrm{pH}$, glucose or $\mathrm{LDH}$. Unfortunately this problem is intrinsic to the design of studies in which the clinician who makes the decision whether or not to drain a parapneumonic effusion has to be aware of the pleural fluid data. Under these circumstances, there is no doubt that a decision to drain is substantially affected by the values of the pleural fluid features. We do not believe that it is realistic to conduct a clinical study like the present one in which the clinician would be blinded to the pleural fluid features. A large prospective study may be conducted to answer whether pleural fluid markers can predict the clinical outcome (death, need for surgery, duration of hospital stay) more accurately than $\mathrm{pH}$ or glucose. Finally, a possible flaw of our study is the over-presentation of PPE in the study population. Despite the fact that our population was carefully selected and evaluated, this may result in an overestimation of the diagnostic values of MMPs and it is an additional reason for further validation of our results in a different, large cohort.

In conclusion, our findings suggest that increased levels of pleural fluid MMP-8 and MMP-9 and decreased levels of MMP-2 are features of pleural space infection in patients with PPE, and such measurements may be helpful in the differentiation between UPPE and CPPE. The pleural fluid content of the above MMPs along with imaging data and the clinical presentation of the individual patient may contribute in the early identification of $\mathrm{CPPE}$ that need to be drained. The findings of the present study require further validation in a large prospective study dealing with the treatment and outcome of unselected patients with PPE before MMPs become part of a clinically meaningful practice. 


\section{References}

$\nabla_{1}$ Birkedal-Hansen $\mathrm{H}$, Moore WG, Bodden MK, Windsor LJ, Birkedal-Hansen B, DeCarlo A, Engler JA: Matrix metalloproteinases: a review. Crit Rev Oral Biol Med 1993; 4:197-250.

$\checkmark 2$ Lemaitre V, D’Armiento J: Matrix metalloproteinases in development and disease. Birth Defects Res C Embryo Today 2006;78: $1-10$.

-3 Vu TH, Werb Z: Matrix metalloproteinases: effectors of development and normal physiology. Genes Dev 2000;14:2123-2133.

$\checkmark 4$ Egeblad M, Werb Z: New functions for the matrix metalloproteinases in cancer progression. Nat Rev Cancer 2002;2:161-174.

5 Folgueras AR, Pendas AM, Sanchez LM, Lopez-Otin C: Matrix metalloproteinases in cancer: from new functions to improved inhibition strategies. Int J Dev Biol 2004;48: 411-424.

6 Cataldo DD, Gueders M, Munaut C, Rocks N, Bartsch P, Foidart JM, Noel A, Louis R: Matrix metalloproteinases and tissue inhibitors of matrix metalloproteinases mRNA transcripts in the bronchial secretions of asthmatics. Lab Invest 2004;84:418-424.

-7 Simpson JL, Scott RJ, Boyle MJ, Gibson PG: Differential proteolytic enzyme activity in eosinophilic and neutrophilic asthma. Am J Respir Crit Care Med 2005;172:559-565.

$>8$ Shapiro SD: Proteinases in chronic obstructive pulmonary disease. Biochem Soc Trans 2002;30:98-102.

-9 Demedts IK, Brusselle GG, Bracke KR, Vermaelen KY, Pauwels RA: Matrix metalloproteinases in asthma and COPD. Curr Opin Pharmacol 2005;5:257-263.

-10 Fligiel SE, Standiford T, Fligiel HM, Tashkin D, Strieter RM, Warner RL, Johnson KJ, Varani J: Matrix metalloproteinases and matrix metalloproteinase inhibitors in acute lung injury. Hum Pathol 2006;37:422-430.

-11 Fukuda Y, Ishizaki M, Kudoh S, Kitaichi M, Yamanaka N: Localization of matrix metalloproteinases-1, -2 , and -9 and tissue inhibitor of metalloproteinase-2 in interstitial lung diseases. Lab Invest 1998;78:687-698.

-12 Eickelberg O, Sommerfeld CO, Wyser C, Tamm M, Reichenberger F, Bardin PG, Soler M, Roth M, Perruchoud AP: MMP and TIMP expression pattern in pleural effusions of different origins. Am J Respir Crit Care Med 1997;156:1987-1992.

-13 Hurewitz AN, Zucker S, Mancuso P, Wu CL, Dimassimo B, Lysik RM, Moutsiakis D: Human pleural effusions are rich in matrix metalloproteinases. Chest 1992;102:1808-1814.
14 Iglesias D, Alegre J, Aleman C, Ruiz E, Soriano T, Armadans LI, Segura RM, Angles A, Monasterio J, de Sevilla TF: Metalloproteinases and tissue inhibitors of metalloproteinases in exudative pleural effusions. Eur Respir J 2005;25:104-109.

15 Sheen P, O'Kane CM, Chaudhary K, Tovar M, Santillan C, Sosa J, Caviedes L, Gilman RH, Stamp G, Friedland JS: High MMP-9 activity characterises pleural tuberculosis correlating with granuloma formation. Eur Respir J 2009;33:134-141.

16 Park KJ, Hwang SC, Sheen SS, Oh YJ, Han $\mathrm{JH}$, Lee KB: Expression of matrix metalloproteinase-9 in pleural effusions of tuberculosis and lung cancer. Respiration 2005;72: 166-175.

17 Zucker S, Mirza H, Conner CE, Lorenz AF, Drews MH, Bahou WF, Jesty J: Vascular endothelial growth factor induces tissue factor and matrix metalloproteinase production in endothelial cells: conversion of prothrombin to thrombin results in progelatinase a activation and cell proliferation. Int J Cancer 1998; 75:780-786.

18 Jantz MA, Antony VB: Pathophysiology of the pleura. Respiration 2008;75:121-133.

19 Davies CW, Kearney SE, Gleeson FV, Davies RJ: Predictors of outcome and long-term survival in patients with pleural infection. Am J Respir Crit Care Med 1999;160:1682-1687.

20 Koegelenberg CF, Diaconi AH, Bolligeri CT: Parapneumonic pleural effusion and empyema. Respiration 2008;75:241-250.

21 Porcel JM, Vives M, Esquerda A: Tumor necrosis factor-alpha in pleural fluid: a marker of complicated parapneumonic effusions. Chest 2004;125:160-164.

22 Jimenez Castro D, Diaz G, Perez-Rodriguez E, Light RW: Prognostic features of residual pleural thickening in parapneumonic pleural effusions. Eur Respir J 2003;21:952-955.

23 Light RW: A new classification of parapneumonic effusions and empyema. Chest 1995; 108:299-301.

24 Kalomenidis I, Bouros D: Pleural fluid pH in parapneumonic pleural effusions: drawing the line. Respiration 2005;72:345-346.

25 Porcel JM, Vives M, Esquerda A, Ruiz A: Usefulness of the British Thoracic Society and the American College of Chest Physicians guidelines in predicting pleural drainage of non-purulent parapneumonic effusions. Respir Med 2006;100:933-937.
26 Pardo A, Selman M: Matrix metalloproteases in aberrant fibrotic tissue remodeling. Proc Am Thorac Soc 2006;3:383-388.

27 Tsilioni I, Gourgoulianis K, Kiropoulos T: Oxidative stress and pleural effusions. Eur Respir J 2008;32(suppl 52):A21.

28 Papageorgiou E, Kostikas K, Kiropoulos T, Karetsi E, Mpatavanis G, Gourgoulianis KI: Increased oxidative stress in exudative pleural effusions: a new marker for the differentiation between exudates and transudates? Chest 2005;128:3291-3297.

29 Davies CW, Gleeson FV, Davies RJ: BTS guidelines for the management of pleural infection. Thorax 2003;58(suppl 2):ii18-ii28.

30 Pneumatikos I, Bouros D: Pleural effusions in critically ill patients. Respiration 2008;76: 241-248.

31 Light RW, Macgregor MI, Luchsinger PC, Ball WC Jr: Pleural effusions: the diagnostic separation of transudates and exudates. Ann Intern Med 1972;77:507-513.

32 Marshall BC, Santana A, Xu QP, Petersen MJ, Campbell EJ, Hoidal JR, Welgus HG: Metalloproteinases and tissue inhibitor of metalloproteinases in mesothelial cells: cellular differentiation influences expression. J Clin Invest 1993;91:1792-1799.

33 Martin J, Yung S, Robson RL, Steadman R, Davies M: Production and regulation of matrix metalloproteinases and their inhibitors by human peritoneal mesothelial cells. Perit Dial Int 2000;20:524-533.

34 Colice GL, Curtis A, Deslauriers J, Heffner J, Light R, Littenberg B, Sahn S, Weinstein RA, Yusen RD: Medical and surgical treatment of parapneumonic effusions: an evidencebased guideline. Chest 2000;118:1158-1171.

35 Heffner JE, Brown LK, Barbieri C, DeLeo JM: Pleural fluid chemical analysis in parapneumonic effusions: a meta-analysis. Am J Respir Crit Care Med 1995;151:1700-1708.

36 Alegre J, Jufresa J, Segura R, Ferrer A, Armadans L, Aleman C, Marti R, Ruiz E, Fernandez de Sevilla T: Pleural-fluid myeloperoxidase in complicated and noncomplicated parapneumonic pleural effusions. Eur Respir J 2002;19:320-325.

37 Porcel JM, Galindo C, Esquerda A, Trujillano J, Ruiz-Gonzalez A, Falguera M, Vives M: Pleural fluid interleukin-8 and C-reactive protein for discriminating complicated nonpurulent from uncomplicated parapneumonic effusions. Respirology 2008;13:5862. 